OPEN ACCESS

Edited by:

Cyril Corbet,

Fonds National de la Recherche Scientifique (FNRS), Belgium

Reviewed by:

Zahra Shahsavari,

Shahid Beheshti University of Medical

Sciences, Iran

Sunwoo Park,

Korea University, South Korea

*Correspondence:

Chase Gross

ccgross@colostate.edu

Specialty section:

This article was submitted to Pharmacology of Anti-Cancer Drugs,

a section of the journal

Frontiers in Pharmacology

Received: 14 June 2021

Accepted: 31 July 2021

Published: 11 August 2021

Citation:

Gross C, Ramirez DA, McGrath S and

Gustafson DL (2021) Cannabidiol

Induces Apoptosis and Perturbs Mitochondrial Function in Human and

Canine Glioma Cells.

Front. Pharmacol. 12:725136.

doi: 10.3389/fphar.2021.725136

\section{Cannabidiol Induces Apoptosis and Perturbs Mitochondrial Function in Human and Canine Glioma Cells}

\author{
Chase Gross $^{1 *}$, Dominique A. Ramirez ${ }^{1}$, Stephanie McGrath ${ }^{1}$ and Daniel L. Gustafson ${ }^{1,2}$ \\ ${ }^{1}$ Department of Clinical Sciences, Colorado State University, Fort Collins, CO, United States, ${ }^{2}$ University of Colorado Cancer \\ Center, Aurora, CO, United States
}

Cannabidiol (CBD), the major non-psychoactive compound found in cannabis, is frequently used both as a nutraceutical and therapeutic. Despite anecdotal evidence as an anticancer agent, little is known about the effect CBD has on cancer cells. Given the intractability and poor prognoses of brain cancers in human and veterinary medicine, we sought to characterize the in vitro cytotoxicity of CBD on human and canine gliomas. Glioma cells treated with CBD showed a range of cytotoxicity from 4.9 to $8.2 \mu \mathrm{g} / \mathrm{ml}$; canine cells appeared to be more sensitive than human. Treatment with $>5 \mu \mathrm{g} / \mathrm{ml}$ CBD invariably produced large cytosolic vesicles. The mode of cell death was then interrogated using pharmacologic inhibitors. Inhibition of apoptosis was sufficient to rescue CBD-mediated cytotoxicity. Inhibition of RIPK3, a classical necroptosis kinase, also rescued cells from death and prevented the formation of the large cytosolic vesicles. Next, cellular mitochondrial activity in the presence of CBD was assessed and within 2 hours of treatment $\mathrm{CBD}$ reduced oxygen consumption in a dose dependent manner with almost complete ablation of activity at $10 \mu \mathrm{g} / \mathrm{ml}$ CBD. Fluorescent imaging with a mitochondrialspecific dye revealed that the large cytosolic vesicles were, in fact, swollen mitochondria. Lastly, calcium channels were pharmacologically inhibited and the effect on cell death was determined. Inhibition of mitochondrial channel VDAC1, but not the TRPV1 channel, rescued cells from CBD-mediated cytotoxicity. These results demonstrate the cytotoxic nature of CBD in human and canine glioma cells and suggest a mechanism of action involving dysregulation of calcium homeostasis and mitochondrial activity.

Keywords: cancer, pharmacology, anti-cancer agents, glioma, brain/CNS tumor, cannabidiol (CBD), mitochondria

\section{INTRODUCTION}

The prognosis following a glioma diagnosis is notoriously grave, no matter the species. High grade gliomas portend a median survival rate of $14-16$ months in human (Stupp et al., 2009) and 2-4 months in canine patients (Rossmeisl et al., 2012). Tumor cell resistance to the currently available multimodal treatments underlies these dismal prognoses. Unfortunately, improvements in patient outcome have not paralleled the medical advances in glioma treatment regimens (Hadziahmetovic et al., 2011; Uhm and Porter, 2017). This highlights the crucial need for further brain cancer treatment research.

Recently, the cannabinoid family, a group of pharmacologically active compounds that primarily interact with specific cannabinoid G-protein coupled receptors (GPCR) (Hermanson and Marnett, 2011), are being rigorously studied for their putative anti-tumorigenic and therapeutically relevant 
properties. These effects have been observed among a diverse family of cannabinoid compounds, such as naturally occurring cannabinoids, synthetic cannabinoid agonists, and endocannabinoid modulators (Hermanson and Marnett, 2011). In particular, cannabidiol (CBD), a non-psychoactive phytocannabinoid derived from Cannabis sativa, has seen accumulating evidence it may function as an antineoplastic agent. CBD has been demonstrated to possess antiproliferative, cytotoxic, anti-migratory, anti-adhesive, antiinvasive, and anti-neovascularization effects in a wide variety of histogenetically diverse cancer types in vitro (Jacobsson et al., 2000; Calvaruso et al., 2012; Massi et al., 2013). The observed cytotoxicity is hypothesized to result from activation of apoptotic and autophagic pathways, with a particular interest in the involvement of the Voltage Dependent Anion Channel 1 (VDAC1) ion channel (Calvaruso et al., 2012; Rimmerman et al., 2013). However, the exact mechanism(s) of these antineoplastic effects remain nebulous.

Current use of cannabinoids in cancer therapy is predominantly through non-prescription cannabis, including tetrahydrocannabinol (THC) or related cannabinoid agonists for alleviation of unwanted concomitant effects of chemo- and radiotherapeutic regimens. While THC and similar cannabinoids are effective in palliative uses, patients often experience unwanted psychoactive effects, tolerance to, and potentially dependence upon these treatments. CBD, in addition to being non-psychotropic, exhibits several therapeutically beneficial effects such as analgesia, anxiolysis, and antiinflammatory properties (Dzierżanowski, 2019).

Cannabinoids exert their pharmacological effects through a wide variety of receptor-dependent and independent interactions. These interactions are capable of modifying signaling pathways that are crucial in tumorigenesis, cancer growth, and metastasis (Kendall and Yudowski, 2016). The cannabinoid-specific GPCRs $\mathrm{CB} 1$ and $\mathrm{CB} 2$ make up the predominant population of the endocannabinoid system (Zou and Kumar, 2018). CB1 is one the most common GPCR in the human and canine brain (Zou and Kumar, 2018; Silver, 2019). CBD has low binding affinity to the cannabinoid receptors, but is capable of modifying them and exerting effects through a diverse cornucopia of other receptors including, but not limited to: TRPV1, mTOR, PPAR, GABA, and 5HT receptors (Zador and Wollemann, 2015; O’Sullivan, 2016; Bakas et al., 2017; De Gregorio et al., 2019). The TRPV1 receptor has been implicated in many of CBD's clinical effects such as analgesia (Zador and Wollemann, 2015). The variable and ubiquitous nature of the cannabinoid signaling system in the brain results in diverse modification of crucial cellular pathways and suggests a potential for utilizing $\mathrm{CBD}$ as a targetable pharmacophore. Further detailing of these interactions will provide invaluable information about CBD's effects on cells and reveal further potential of CBD as a therapeutic.

Several studies have demonstrated the remarkable similarities between canine and human gliomas, including MRI characteristics, histological and immunohistochemical features, genetic conservation, and immunological responses (Thomas et al., 2009; Herranz et al., 2016; Koehler et al., 2018). Thus, spontaneously occurring canine gliomas serve as an ideal surrogate for human brain tumors. The present study explores the anti-cancer phenomena of CBD in human and canine glioma cells in vitro and details the biochemical mechanisms responsible as a foundation for development of CBD as a potential clinical therapeutic.

\section{MATERIALS AND METHODS}

\section{Cell Culture and Reagents}

Two canine glioma cells lines (J3TBG, SDT3G) were provided by UC Davis. J3TBG was derived from a grade III astrocytoma and SDT3G from a grade III glioblastoma sample (York et al., 2018). The human cell line U87MG was purchased from the University of Colorado Anschutz Tissue Culture Shared Resource (PMTSR). The human cell line U373MG Uppsala was purchased from the ECACC. All cell lines were cultured in Minimum Essential Media Eagle (MEM; Corning, Inc. Corning, NY) supplemented with $10 \%$ FBS, $100 \mathrm{U} / \mathrm{ml}$ streptomycin, $4.5 \mathrm{~g} / \mathrm{L}$ glucose and $10 \mathrm{mM}$ sodium pyruvate at $37^{\circ} \mathrm{C}$, in $5 \% \mathrm{CO}_{2}$. Cell cultures were maintained in semiconfluent monolayers and passaged 1-2 times per week. Cell lines were maintained for no more than 30 passages, at which time a new stock was utilized. All cell lines were verified by STR (Short Tandem Repeats) at the Flint Animal Cancer Center Cell Line Validation Core at Colorado State University. Cells were verified to be mycoplasma-free via PCR prior to transduction with the IncuCyte ${ }^{\mathrm{TM}}$ NucLight Red lentiviral system (Essen Bioscience Inc., Ann Arbor, MI) and were selected with puromycin following transduction. CBD was provided by Extract Labs (Boulder, CO) and analyzed for purity. Two forms of CBD-dominant products were provided: highlypurified $\mathrm{CBD}$ isolate ( $>99.9 \%$ pure cannabidiol) and $\mathrm{CBD}$ extract (96\% CBD, 4\% cannabinoid diverse). Both forms of CBD were prepared as a stock solution in DMSO, and later diluted to $100 \mathrm{x}$ working stocks in 50/50 ethanol/ultra-pure water. $z-V A D$-fmk (final concentration of $50 \mu \mathrm{M}$ (Lincoln et al., 2018), dissolved in 50/50 ethanol/ultra-pure water), necrostatin-1 (final concentration of $100 \mu \mathrm{M}$ (Huang et al., 2013), dissolved in DMSO/ultra-pure water), and VX-765 (final concentration of $50 \mu \mathrm{M}$ (McKenzie et al., 2018), dissolved in 50/50 ethanol/ultra-pure water) were purchased from Sigma-Aldrich (MilliporeSigma; Burlington, MA). GSK'872 (final concentration of $1 \mu \mathrm{M}$ (Mandal et al., 2014), dissolved in 50/50 ethanol/ultra-pure water), 4,4'Diisothiocyano-2,2'-stilbenedisulfonic acid (DIDS) (final concentration of $50 \mu \mathrm{M}$ (Benitez-Rangel et al., 2015), dissolved in 50/50 ethanol/ultra-pure water), and 5-IRTX (final concentration of $1 \mu \mathrm{M}$ ) (Stampanoni Bassi et al., 2019), dissolved in 50/50 ethanol/ultra-pure water) were purchased from Tocris Bioscience (Bristol, United Kingdom). Concentrations of reagents were determined using previously published inhibitory values. 


\section{Cytotoxicity Assays}

Cells were seeded in 96-well Nunclon Delta Surface Plate (Thermo-Scientific, Rockford, IL) at densities to ensure midlate log phase growth at $96 \mathrm{~h}$ (3,000 cells/well). Cells were allowed to adhere for a minimum of $4 \mathrm{~h}$ before dosing. Cell viability was quantified utilizing the membrane impermeable dye YOYO-1 (Thermo-Scientific, Rockford, IL) at $100 \mathrm{nM}$. Assays were imaged every $3 \mathrm{~h}$ using IncuCyte ${ }^{\mathrm{TM}}$ Zoom (Essen Bioscience, Ann Arbor, MI). At $96 \mathrm{~h}$, the percentage of dead cells was calculated by dividing the measured final green fluorescence (a surrogate of cell death) by the sum of the final red fluorescence per $\mathrm{mm}^{2}$ (a surrogate of cell viability) and green fluorescence per $\mathrm{mm}^{2}$. Subgroups in biological replicates were performed in technical triplicate. Bars represent the mean across $n=4$ biological replicates, and the error bars represent the standard deviation between biological replicates.

\section{Seahorse XFe24 Assays}

Cells were resuspended in Seahorse XF DMEM (Agilent Technologies, Santa Clara, CA) supplemented with $100 \mu \mathrm{g} /$ $\mathrm{ml}$ streptomycin, $4.5 \mathrm{~g} / \mathrm{L}$ glucose, and $10 \mathrm{mM}$ sodium pyruvate. Cells were plated at an empirically determined density of $7.5 \times 10^{4}$ cells/well in Cell-Tak (Corning, Inc. Corning, NY) treated XF24 cell culture microplates (V7-PS; Seahorse Bioscience, North Billerica, MA). Cells were then spun at $500^{\star} \mathrm{g}$ for $5 \mathrm{~min}$ and allowed to equilibrate in a $37^{\circ} \mathrm{C}$ non- $\mathrm{CO}_{2}$ incubator immediately before metabolic flux analysis. Oxygen Consumption Rate/Extracellular Acidification Rate (OCR/ECAR) were then measured by the Agilent Seahorse XFe24 Analyzer (Agilent Technologies, Santa Clara, CA) under basal conditions for $30 \mathrm{~min}$ and post-injection of compounds. The data were then validated by injection of oligomycin $(18.5 \mu \mathrm{M})$, rotenone/antimycin A $(6.6 \mu \mathrm{M})$, and carbonyl cyanide $m$-chlorophenyl hydrazine $(6 \mu \mathrm{M})$. Biological replicates were performed in technical triplicate. Data shown are from $n=3$ independent biological replicates until $\mathrm{x}=$ $267 \mathrm{~min}$, the subsequent data is from $n=2$ independent biological replicates.

\section{Live Cell Imaging and Mitochondria Staining} NucLight-Red transfected cells (SDT3G and U373MG) were plated onto Cellvis 8-well chambered cover glass $(\mathrm{C} 8-1.5 \mathrm{H}-\mathrm{N}$, Cellvis, Mountain View CA) in DMEM at a density to ensure $50-70 \%$ confluency at the time of dosing for live cell imaging studies. Cells were dosed with CBD after adhering to the cover glass. Incubation times as indicated were staggered such that all incubations would end at the time of imaging. Cells were stained with both MitoTracker Deep Red FM (M22426, ThermoFisher, Waltham MA) and Hoescht (33342, ThermoFisher, Waltham MA) prior to imaging. During the staining and imaging, cells were maintained in phenol redfree supplemented DMEM, termed "imaging media," containing the following: penicillin/streptomycin (15140163, Gibco), L-glutamine (A2916801, Gibco), essential (11130-051, Gibco) and nonessential (11140-076, Gibco) amino acids all diluted to a final of $1 \mathrm{x}$ from the stock, and sodium bicarbonate (S233-500, Fisher, Waltham MA) at a final concentration of $1.5 \%$. Before the end of the incubation, cells were washed once with imaging media and were stained with $50 \mathrm{nM}$ MitoTracker diluted in imaging media for $15 \mathrm{~min}$ at $37^{\circ} \mathrm{C}$ followed by $10 \mu \mathrm{M}$ Hoescht for $5 \mathrm{~min}$ at room temperature. $\mathrm{CBD}$ was maintained at appropriate concentrations for the staining and imaging steps. Live cell images were then visualized using an Olympus IX83 (Olympus, Tokyo, Japan) confocal microscope and Hamamatsu ORCA-R2 (Hamamatsu Photonics, Shizuoka, Japan) digital camera. Visual information corresponding to nuclear RFP (NucLight-Red) were captured for analysis but were excluded from the publication images.

\section{ATP Luminescence Assay}

Cellular ATP levels were measured using a luminescent ATP detection assay kit according to the manufacturer's instruction (ab113849, Abcam, Cambridge, MA). Cells were seeded at a density of 3,000 cells/well, allowed to adhere for $4 \mathrm{~h}$, and dosed in the same method as the cytotoxicity assays. Luminescence of luciferase was read via a BioTek Synergy HTX 96-well microplate reader (Biotek, Winooski, VT). ATP concentration for individual wells was interpolated via standard curve in GraphPad Prism (GraphPad Software, Santa Clara, CA). Luminescence of cell culture media was subtracted from each well. Data was then averaged, corrected for proliferation, and subsequently normalized to their respective controls. Biological replicates were performed in technical triplicate. Data shown are from $n=2$ independent biological replicates.

\section{Resazurin Metabolic Assay}

Resazurin sodium salt was purchased from Sigma-Aldrich (MilliporeSigma; Burlington, MA). Cells were seeded at a density of 3,000 cells/well, allowed to adhere for $4 \mathrm{~h}$, and were subsequently dosed with varying conditions $(0-20 \mu \mathrm{g})$ for a final well volume of $180 \mu \mathrm{L}$. Wells were dosed with same methods as cytotoxicity assays. After $96 \mathrm{~h}, 20 \mu \mathrm{L}$ of resazurin reagent was added to each well for a final well volume of $200 \mu \mathrm{L}$. Cells were then incubated for $4 \mathrm{~h}$ in standard culture conditions. Resazurin reagent reduction, a surrogate of cell metabolism, was measured via fluorescence (excitation: $540 \mathrm{~nm}$; emission: $590 \mathrm{~nm}$ ) in a 96-well microplate reader. DMEM control fluorescence was subtracted for each well. Fluorescence data was averaged and subsequently normalized to their respective controls. Assays were performed in biological and technical triplicate: the bars represent the mean across biological replicates and the error bars represent the Standard Deviation between biological replicates.

\section{Data Analysis}

Statements of technical and biological replicates for each assay are included in the respective method subsection and in the figure legends. Statistical tests were only performed for assays with biological replicates of $n \geq 3$. All tests used are named in the figure legend with the associated data. Data for statistical analyses were 
A Dose Response

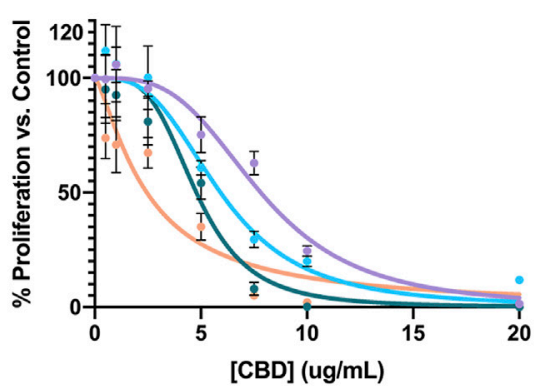

- U87MG

- U373MG Uppsalla

- J3TBG

- SDT3G

C
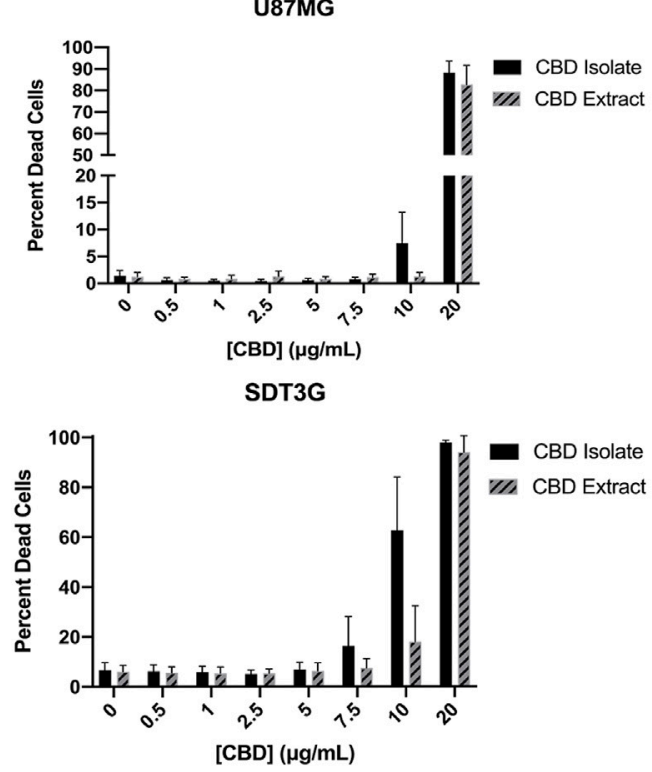

D

(i)

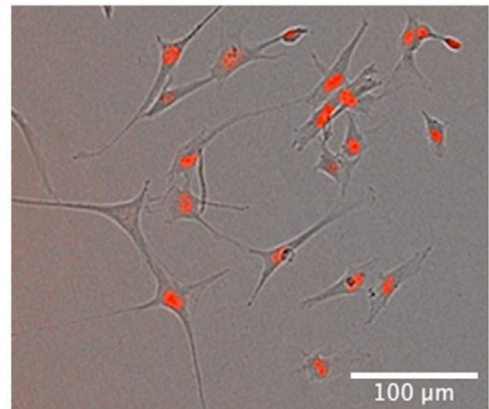

B

\begin{tabular}{|cccc|}
\hline Cell Line & CBD Source & IC $_{\mathbf{5 0}}(\mathrm{ug} / \mathrm{ml})$ & SD \\
\hline J3TBG & Isolate & 5.77 & 0.38 \\
\hline & Extract & 7.23 & 0.37 \\
\hline SDT3G & Isolate & 4.85 & 0.10 \\
\hline & Extract & 6.03 & 0.68 \\
\hline U87MG & Isolate & 8.20 & 0.69 \\
\hline & Extract & 11.20 & 2.33 \\
\hline U373MG Uppsalla & Isolate & 4.94 & 0.79 \\
\hline & Extract & 5.15 & 2.13 \\
\hline
\end{tabular}

U373MG Uppsalla
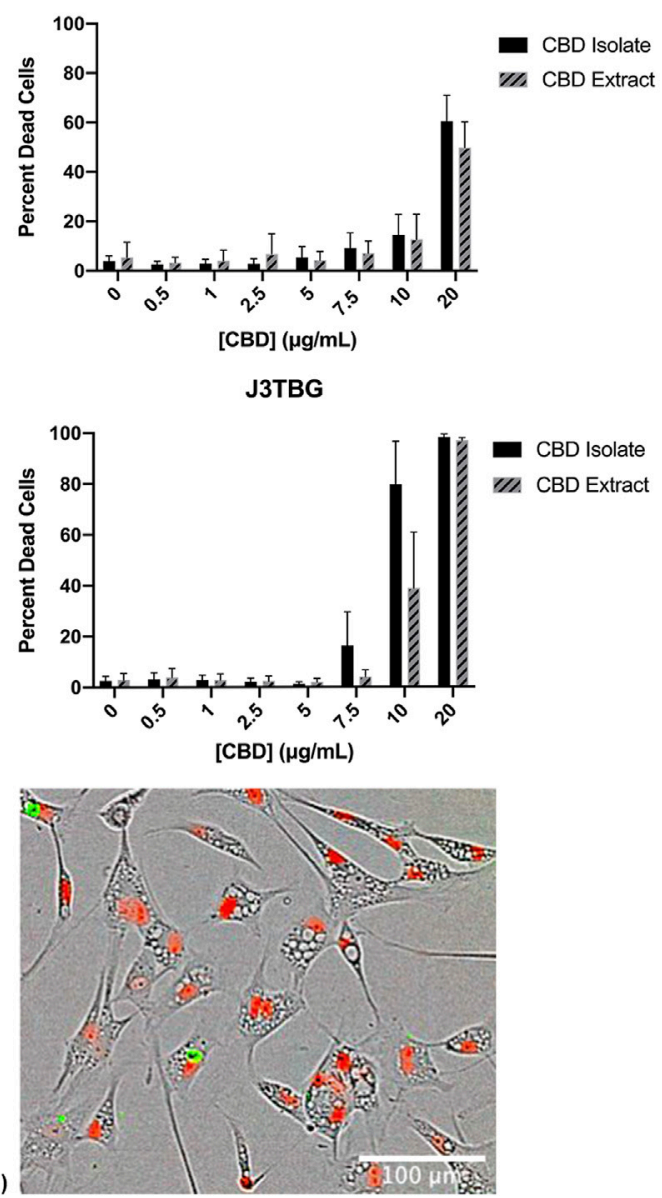

FIGURE 1 | CBD is antiproliferative and cytotoxic to glioma cell lines. (A) U87MG, U373MG, J3TBG, and SDT3G Glioma cells were treated with CBD isolate $(0-20 \mathrm{\mu g} / \mathrm{mll})$ for $96 \mathrm{~h}$. Cell proliferation and dose response were measured via IncuCyte ${ }^{\mathrm{TM}}$ Red Object Count. Data are from $n=4$ independent repeated experiments. Individual points expressed as mean \pm SD, curve fit through a non-linear, variable slope regression (B) $I C_{50}$ values were determined from the curve fits via GraphPad Prism for both CBD isolate and extract at $96 \mathrm{~h}$. Data are from $n=4$ independently repeated experiments (C) U87MG, U373, J3TBG, and SDT3G Glioma cells were treated with CBD isolate or extract $(0-20 \mu \mathrm{g} / \mathrm{ml})$ for $96 \mathrm{~h}$. Cytotoxicity was determined using the green fluorescent dye, YOYO-1. Data are from $n=4$ independently repeated experiments, expressed as mean \pm SD (D) SDT3G glioma cells treated with $0 \mu \mathrm{g} / \mathrm{ml} \mathrm{CBD}$ after $48 \mathrm{~h}$ (i), SDT3G Glioma cells featuring formation of intracellular vesicles after $48 \mathrm{~h}$ of treatment with $7.5 \mu \mathrm{g} / \mathrm{ml} \mathrm{CBD}$ isolate (ii) At $48 \mathrm{~h}$, cell death is not occurring at this concentration. Red fluorescence represents nuclei of viable cells. Images were captured through a 10x Nikon objective.

not explicitly tested for normality, nor were variances between compared groups tested to be statistically significantly different. All measures of variation are reported as standard deviation (SD).
Statistical analyses were carried out using GraphPad Prism 8 (GraphPad Software, La Jolla, CA, United States). An * indicates a calculated $p$-value of $\leq 0.05$. 


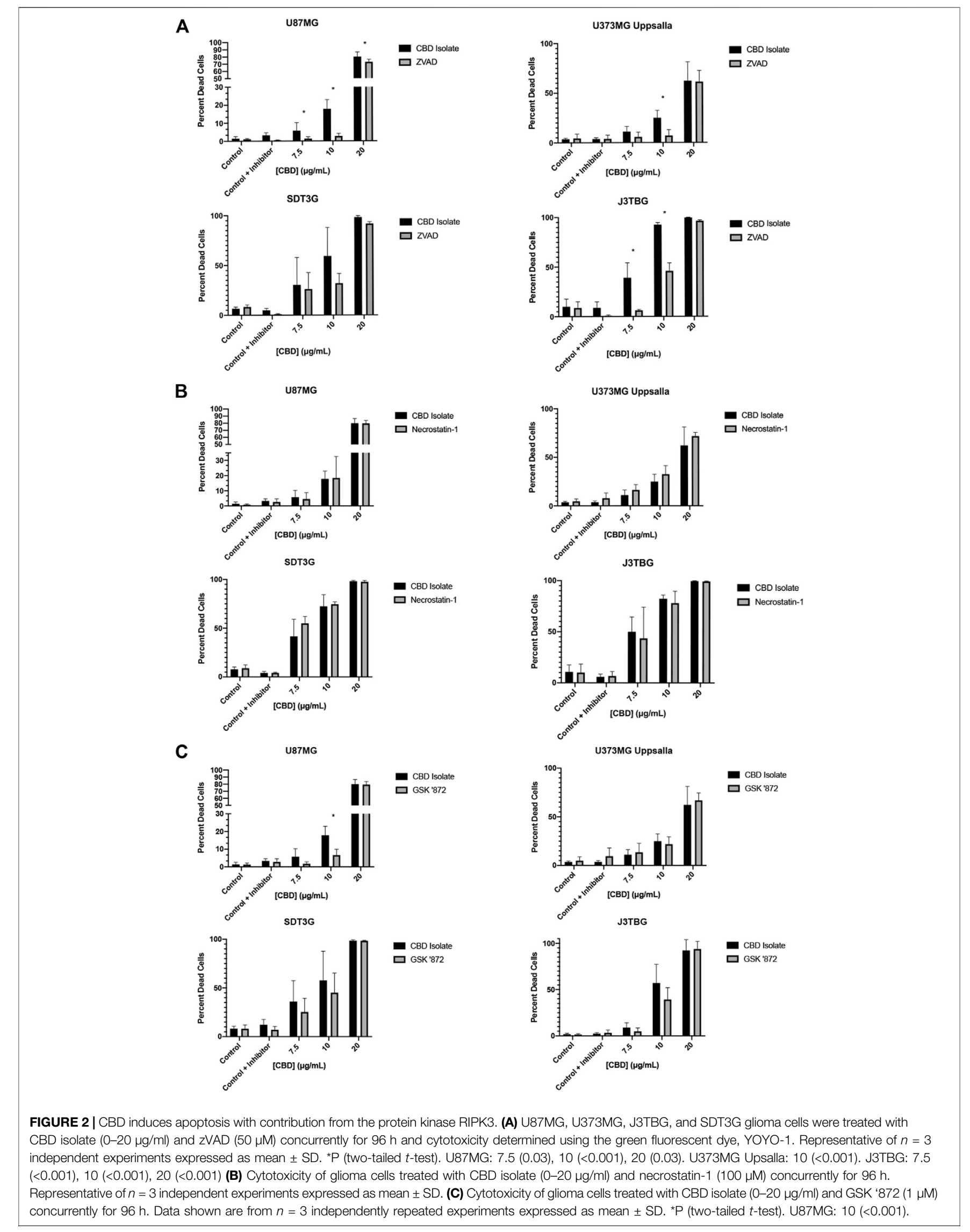




\section{RESULTS}

\section{CBD Is Anti-proliferative, Cytotoxic, and Induces the Formation of Intracellular Vesicles in Glioma Cells}

To investigate the effect of CBD treatment on cell line proliferation and cytotoxicity, we monitored cell viability via the IncuCyte ${ }^{\mathrm{TM}}$ in a selection of glioma cells including canine cell lines SDT3G and J3TBG and human cell lines U87MG and U373MG Uppsala (Figure 1). Two sources of CBD-dominant compounds were used, $>99.9 \%$ pure $\mathrm{CBD}$ isolate, and cannabinoid diverse CBD extract (96\% CBD). Cell proliferation decreased starkly following $\mathrm{CBD}$ isolate treatment (Figures 1A,B). The cytotoxicity of CBD against human and canine gliomas was also confirmed using the live/dead dye YOYO-1 (Figure 1C). This measure of cytotoxicity confirmed cell death at the three highest concentrations $(7.5,10,20 \mu \mathrm{g} / \mathrm{ml})$ for both sources of CBD. In all cases, glioma cells appeared to be marginally more sensitive to $\mathrm{CBD}$ isolate than $\mathrm{CBD}$ extract (Figures 1B,C); later experiments were conducted solely with the highly-purified CBD isolate. Treatment with cytotoxic concentrations of CBD invariably induced the formation of intracellular vesicles (Figure 1D) across all cell lines.

\section{CBD Induces Apoptosis With Involvement From the Necroptotic Kinase RIPK3}

Next, we investigated the mode of cell death involved in CBDmediated cytotoxicity. We investigated three primary means of cell death: apoptosis, necroptosis, and pyroptosis. To observe the contribution of apoptosis, glioma cell lines were treated with CBD $(0-20 \mu \mathrm{g} / \mathrm{ml})$ and $\mathrm{zVAD}$-fmk (zVAD) $(50 \mu \mathrm{M})$, a pan-caspase inhibitor for $96 \mathrm{~h}$ (Figure 2A). At cytotoxic CBD concentrations $(7.5,10,20 \mu \mathrm{g} / \mathrm{ml}), \mathrm{zVAD}$ prevented cell death and rescued cell viability across all cell lines. To observe the contribution of necroptosis, glioma cell lines were treated with $\mathrm{CBD}$ and necrostatin-1 $(100 \mu \mathrm{M})$, a RIPK1 inhibitor. At cytotoxic CBD concentrations, necrostatin-1 was unable to rescue CBD-induced cell death (Figure 2B). As part of our necroptosis investigation, we also inhibited RIPK3, a classically associated necroptotic kinase. Glioma cells were treated with CBD and GSK872 $(1 \mu \mathrm{M})$, a RIPK3 inhibitor and putative inhibitor of necroptosis. At cytotoxic CBD concentrations, GSK872 rescued cells from $\mathrm{CBD}$-induced cell death, but not to the same degree as $\mathrm{zVAD}$, (Figure $2 \mathrm{C}$ ), and prevented the formation of CBD-mediated intracellular vesicles (Supplementary Figure S1A). Finally, we investigated the contribution of caspase-1 mediated pyroptosis as a mode of CBD-mediated cytotoxicity. U87MG and J3TBG Glioma cells were treated with $\mathrm{CBD}$ and VX-765 (Belnacasan, $50 \mu \mathrm{M}$ ), a caspase-1 inhibitor. VX-765 was unable to rescue CBDinduced cell death in either cell line (Supplementary Figure S1B).

To characterize the timeline of CBD-mediated cytotoxicity, glioma cell lines were treated with CBD $(0-20 \mu \mathrm{g} / \mathrm{ml})$ for $96 \mathrm{~h}$. In an effort to rescue cells from CBD-mediated cytotoxicity, sub- groups had the CBD-supplemented media replaced with fresh CBD-free media at 24 and $48 \mathrm{~h}$. Across all cell lines, media replacement at $24 \mathrm{~h}$ was able to generally rescue cell viability, while the media replacement at $48 \mathrm{~h}$ appeared similar to the no replacement control. Our data suggest that a commitment to cell death occurs between 24- and 48-h post CBD exposure (Supplementary Figure S1C). Observed mild discrepancies in rescue between concentrations/cell lines are likely due to the methods used during the wash-off experiments. Cells were likely accidently and unavoidably aspirated, or disturbed during replacement with $\mathrm{CBD}$-free medium. We suspect this discrepancy does not reflect the true biologic phenomena.

\section{CBD Impairs Mitochondrial Activity at Sub-cytotoxic Concentrations}

U87MG and U373MG Uppsala human glioma cells were treated with CBD for $96 \mathrm{~h}$ and cytotoxicity was measured using two methods: (Figure 3A): resazurin reduction (surrogate of cell viability measuring mitochondrial function); and (Figure 3B) cell proliferation using red fluorescence on the IncuCyte ${ }^{\mathrm{TM}}$. Treatment with CBD drastically impairs mitochondrial-based resazurin reduction, suggesting sensitivity at much lower concentrations of CBD than that determined by IncuCyte ${ }^{\mathrm{TM}}$. Thus, CBD impairs mitochondrial activity at sub-cytotoxic concentrations without altering cell proliferation or death. This finding was confirmed via Seahorse XFe24 analysis of mitochondrial OCR (Figure 3C) and ECAR (Supplementary Figure S1D) post-CBD treatment. In all glioma cell lines, we observed a decrease in oxygen consumption reflecting inhibition of mitochondrial respiration that occurs long before detectable cytotoxicity. Treatment with CBD altered cellular ATP production at both sub-cytotoxic and lethal concentrations in a dose-dependent and time-sensitive manner. In all glioma cell lines, a decrease in ATP production after treatment with lethal and sub-cytotoxic concentrations of CBD was observed, further suggesting compromise of mitochondrial function (Figure 3D).

\section{Treatment With a Lethal CBD Concentration Produces Ultrastructural Changes in the Mitochondria}

SDT3G and U373MG cells were stained with MitoTracker Deep Red FM and visualized by live cell imaging to investigate morphological changes related to CBD treatment. The untreated cell lines displayed a fibrillar mitochondrial network distributed throughout the cell (Figure 4A). Each cell line was then treated with a cytotoxic $(10 \mu \mathrm{g} / \mathrm{ml})$ and non-cytotoxic $(2.5 \mu \mathrm{g} / \mathrm{ml})$ dose of $\mathrm{CBD}$ and visualized at time points throughout the known cell-death decision time frame (Supplementary Figure S1C.). Within $2 \mathrm{~h}$ post-treatment, both SDT3G (Figure 4B) and U373MG (Figure 4C) cells showed dramatic alteration of mitochondrial morphology and disruption of the fibrillar network but only at the high CBD concentration. At this concentration the mitochondria were very large and circular. Images for SDT3G at $48 \mathrm{~h}$ post-high dose CBD 

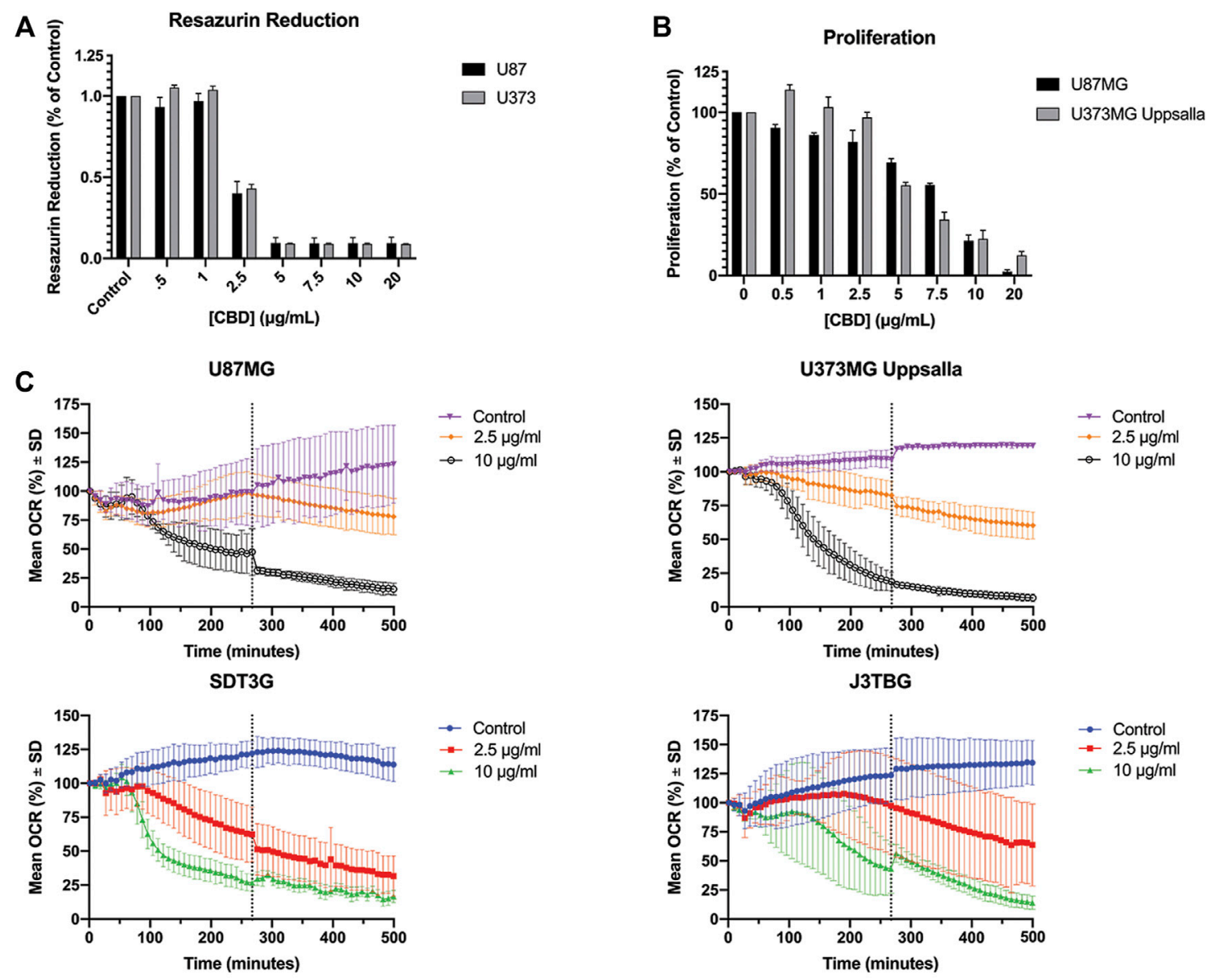

D

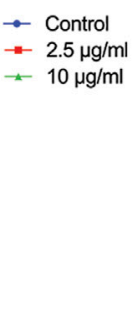

$\rightarrow$ Control
$\rightarrow 2.5 \mu \mathrm{g} / \mathrm{ml}$

$\rightarrow 10 \mu \mathrm{g} / \mathrm{ml}$

U87MG

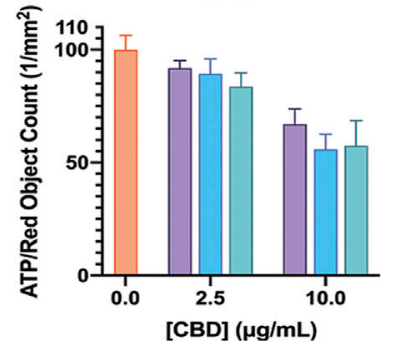

$\square$ Control (48 hrs)

$\square 12$ hours

$\square 24$ hours

$\square 48$ hours

SDT3G
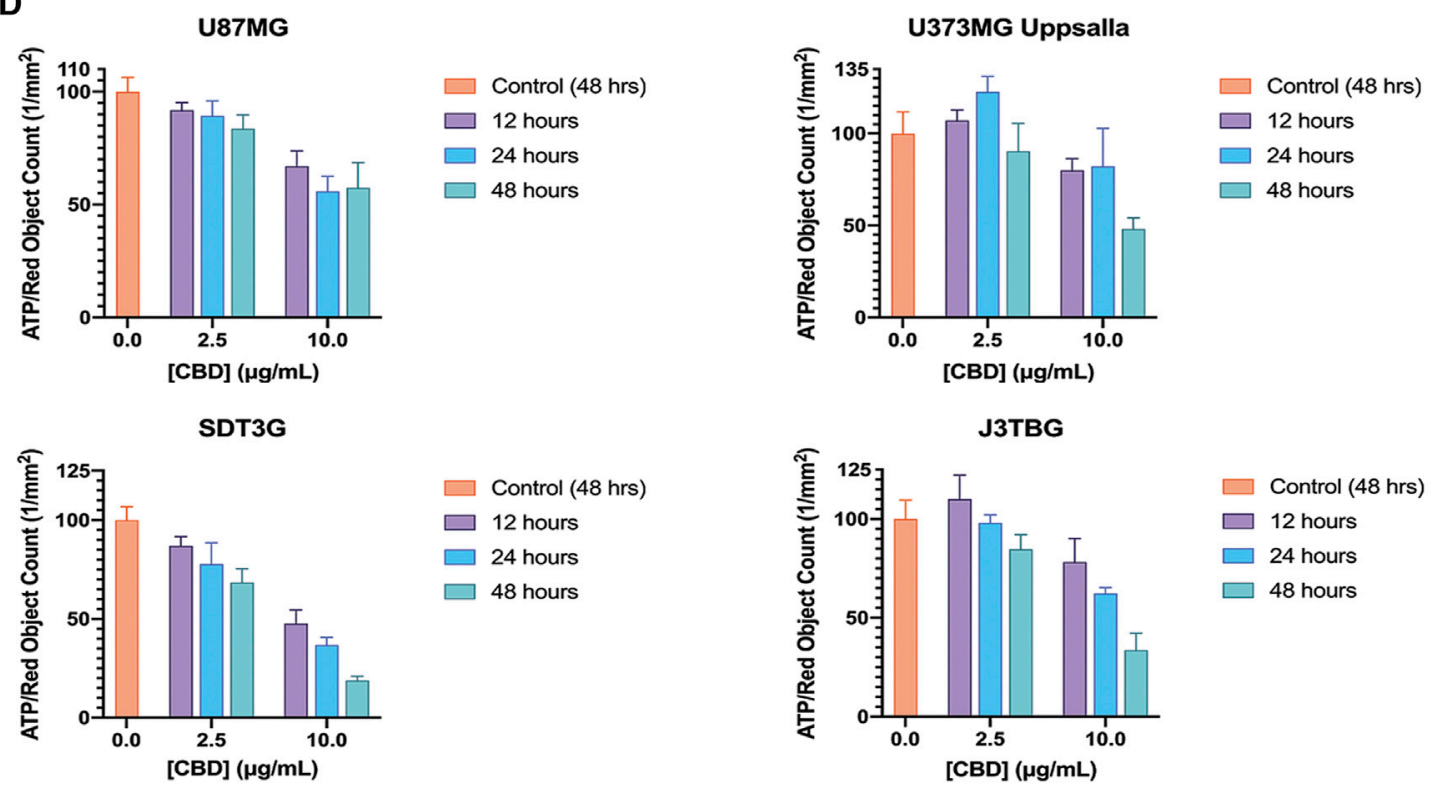

FIGURE 3 |CBD perturbs mitochondrial activity at lethal and non-lethal concentrations. (A) Glioma cell lines U87MG and U373MG Uppsala were treated with CBD isolate (0-20 ug $/ \mathrm{mL}$ ) for $96 \mathrm{~h}$. Cell viability was determined via resazurin-based metabolic assay. Data (arbitrary fluorescence units) were normalized to the vehicle treated control. Representative of $n=3$ independent experiments, expressed as mean \pm SD. (B) Glioma cell lines U87MG and U373MG Uppsala were treated with CBD isolate $(0-20 \mu \mathrm{g} / \mathrm{ml})$ for $96 \mathrm{~h}$. Cell proliferation was measured via IncuCyte ${ }^{\mathrm{TM}}$ Red Object Count. Data shown are from $n=3$ independently repeated experiments,

(Continued) 
FIGURE 3 | expressed as mean \pm SD. (C) Glioma cells were measured for baseline oxygen consumption for $30 \mathrm{~min}$, then treated with $\mathrm{CBD}$ at lethal (10 $\mu \mathrm{g} / \mathrm{ml})$ and nonlethal $(2.5 \mathrm{\mu g} / \mathrm{mll})$ concentrations. OCR was monitored for $500 \mathrm{~min}$ using the SeaHorse XF24. Data shown are from $n=3$ independent biological replicates until $\mathrm{X}=$ $267 \mathrm{~min}$ (vertical dashed grey line) at which point the subsequent data are from $n=2$ independent biological replicates. Data are expressed as mean \pm SD. (D) U87MG, U373, J3Tbg, and SDT3G Glioma cells were treated with CBD isolate $(2.5,10 \mu \mathrm{g} / \mathrm{ml})$ for 12, 24, and $48 \mathrm{~h}$. Cellular ATP production was determined via ATP luminescence kit. Data (fluorescence) were interpolated via standard curve, corrected for proliferation (Red Object Count via Incucyte ${ }^{\mathrm{TM}}$ ) and normalized to the 48-h vehicle treated control. Data shown are from $n=2$ independent experiments. Data are expressed as mean \pm SD.

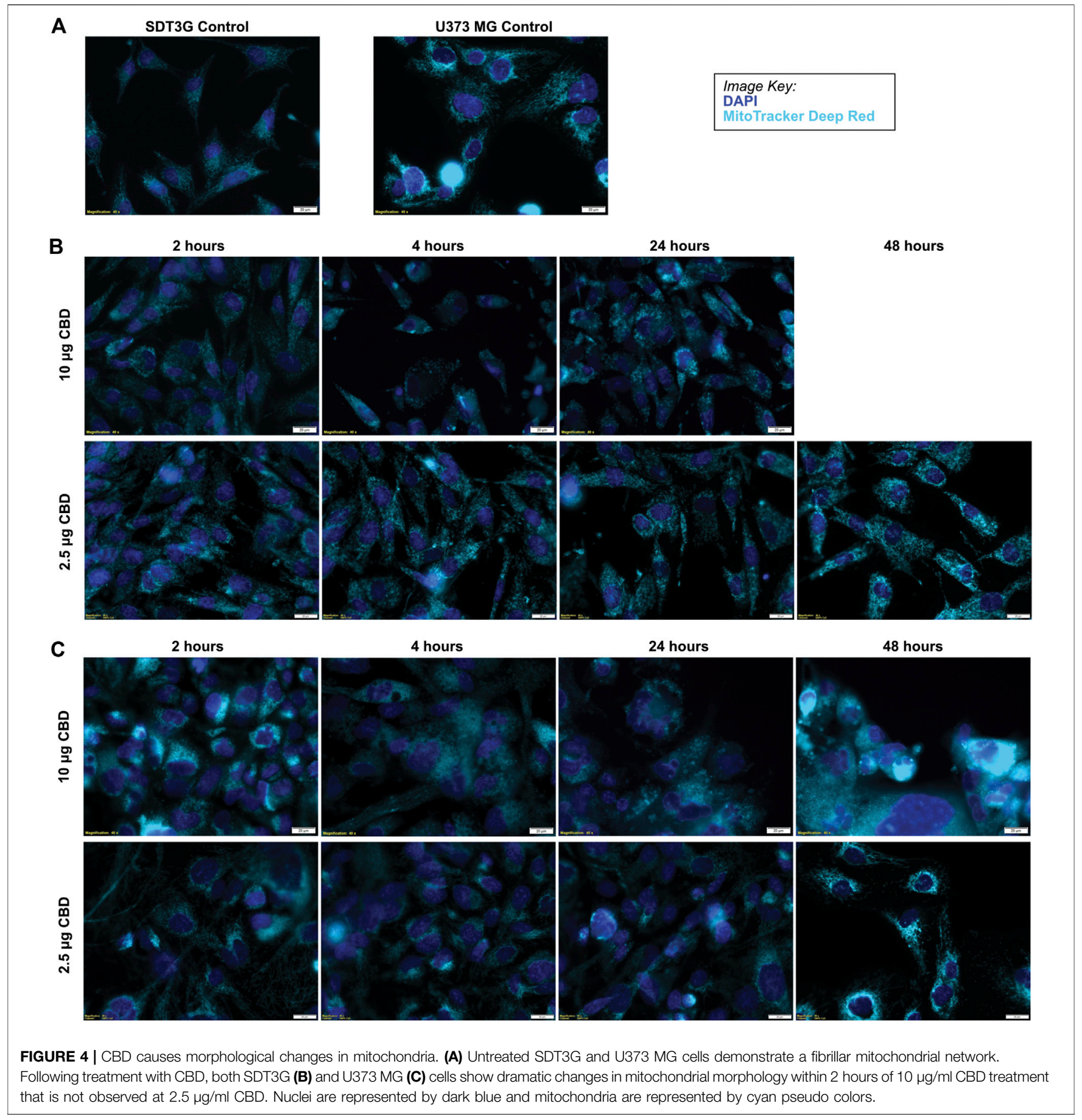



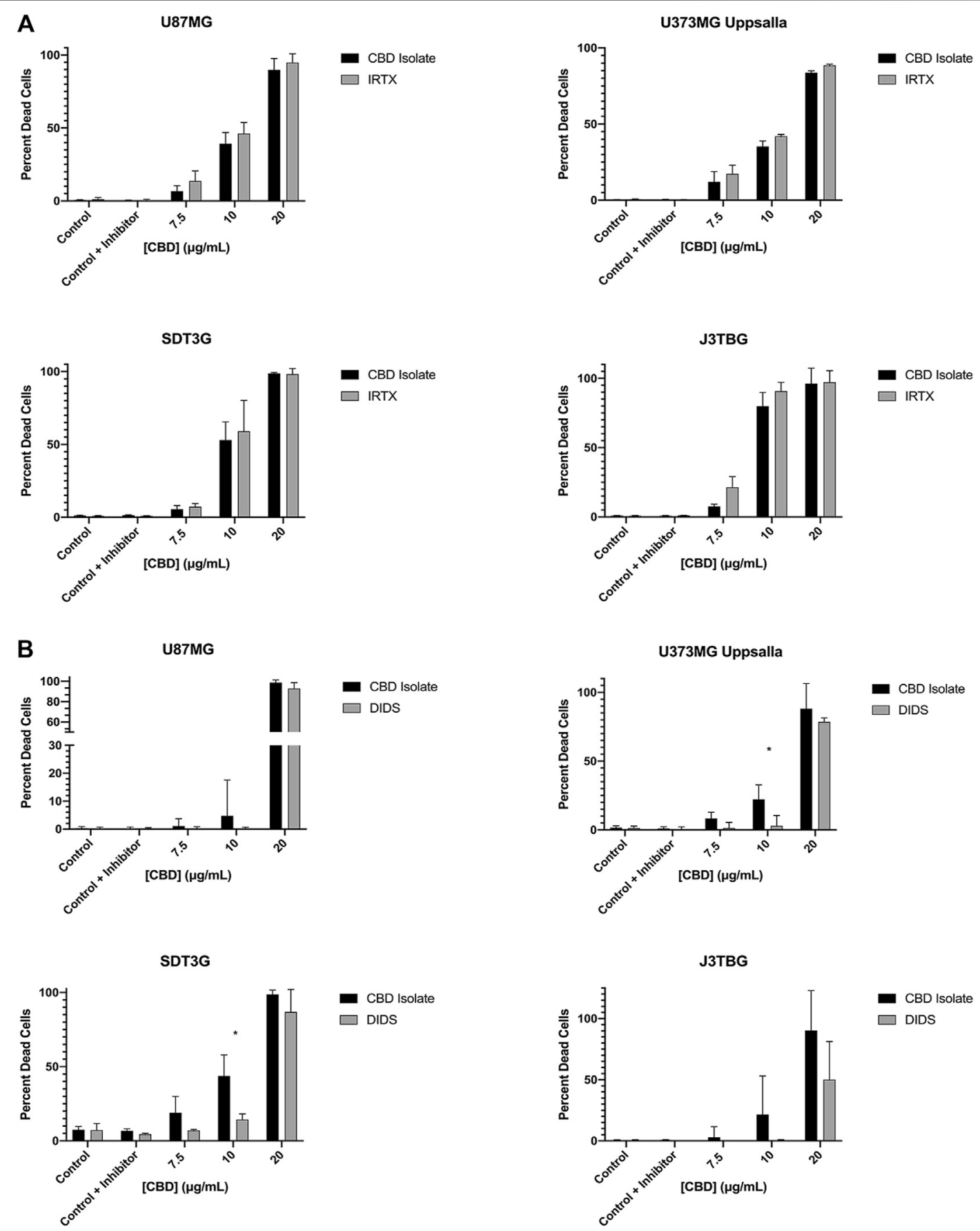

FIGURE 5 | CBD mediated cytotoxicity involves VDAC1 but not TRPV1. (A) U87MG, U373MG, J3TBG, and SDT3G Glioma cells were treated with CBD isolate $(0-20 \mu \mathrm{g} / \mathrm{ml})$ and IRTX $(1 \mu \mathrm{M})$ concurrently for $96 \mathrm{~h}$ and cytotoxicity determined using the green fluorescent dye, YOYO-1. Representative of $n=3$ independent experiments expressed as mean $\pm \mathrm{SD}$. *P (two-tailed $t$-test). (B) Cytotoxicity of glioma cells treated with CBD isolate (0-20 $\mu \mathrm{g} / \mathrm{ml})$ and $\mathrm{DIDS}(50 \mu \mathrm{M}) \mathrm{concurrently}$ for $96 \mathrm{~h}$. Data shown are from $n=3$ independent experiments expressed as mean \pm SD. ${ }^{\star} \mathrm{P}$ (two-tailed $t$-test). U373MG Upsalla: 10 (0.02). SDT3G: 10 (0.003).

treatment could not be captured because no viable cells remained. This phenomenon was not observed at the low CBD concentration where the baseline mitochondrial morphology and network were largely preserved throughout the 48-h time frame. The spherical mitochondria seemingly correspond to the large vesicles observed by brightfield in the IncuCyte ${ }^{\mathrm{TM}}$ (Figure 1D [ii]). J3TBG and U87MG cell lines were not included in this experiment series due to the morphology of the cells; the large nuclei and scant cytoplasm prevented adequate visualization of the mitochondrial morphology. 


\section{CBD-Mediated Cytotoxicity Involves VDAC1 but Not TRPV1}

Cell Lines U87MG, U373MG Uppsala, SDT3G, and J3TBG were treated concurrently with CBD $(0-20 \mu \mathrm{g} / \mathrm{ml})$ and IRTX $(1 \mu \mathrm{M})$, a known inhibitor of TRPV1 (Figure 5A). At cytotoxic CBD concentrations, inhibition of TRPV1 was unable to rescue cell viability. Cell lines were treated with CBD $(0-20 \mu \mathrm{g} / \mathrm{ml})$ and DIDS $(50 \mu \mathrm{M})$, a known inhibitor of the VDAC1 (Figure 5B). At cytotoxic CBD concentrations, inhibition of VDAC1 rescued cell viability similar to that observed following inhibition of apoptosis.

\section{DISCUSSION}

Recent studies with cannabinoids have begun to identify potential activities that may be exploited for anticancer therapy. A wide range of antineoplastic effects on an array of histogenetically diverse cancers, relatively safe therapeutic index, and growing popularity in medicine and society makes them ideal candidates for further research. CBD has consistently induced apoptotic cell death in vitro and in vivo for many types of neoplasia (Shrivastava et al., 2011; Wu et al., 2018; Jeong et al., 2019). While the exact mechanism of action underlying this cytotoxicity has not been fully elucidated, it has been hypothesized that mitochondrial dysfunction precipitated by altering VDAC1 channel activity is central to the observed antiproliferative, apoptotic, and other antineoplastic signaling pathways (Rimmerman et al., 2013; Magrì et al., 2018; Olivas-Aguirre et al., 2019).

In this present study, we demonstrate that highly purified CBD isolate reduced proliferation and induced caspase-mediated cell death, suggestive of apoptosis, in both canine glioma cell lines SDT3G and J3TBG as well as the human glioma cell lines U87MG and U373MG Uppsala. The commitment to CBD-induced apoptotic cell death involves a critical cell fate decision between 24 and $48 \mathrm{~h}$. Our data also demonstrate that RIPK3, a protein kinase classically associated with necroptosis (Orozco and Oberst, 2017), plays an impactful role in CBD-mediated cytotoxicity and formation of intracellular vesicles, suggesting a non-canonical function of the kinase. RIPK3 has been implicated as a proapoptotic adaptor after the formation of the necrosome, particularly when the core necroptotic machinery component Mixed Lineage Kinase domain-like protein (MLKL) is absent (Mandal et al., 2014; Newton et al., 2014; Orozco and Oberst, 2017). Interestingly, the domestic dog (Canis lupus familiaris) does not possess the MLKL gene (Dondelinger et al., 2016), perhaps highlighting an even more central role for RIPK3 in determining CBD sensitivity in canine gliomas. In addition, RIPK3 has also been implicated in the execution of mitochondrial-mediated apoptosis in cardiac myocytes during hypoxic insult via inhibition of the FUNDC1 pathway, and thereby inhibition of mitophagy, a selective degradation of damaged mitochondria (Zhou et al., 2017). Future investigation of these potential phenomena may help to clarify the exact biophysical mechanisms behind CBD-mediated cytotoxicity in glioma cells.
The effects of the cannabinoid family are extremely diverse and their exact mechanisms tend to be incompletely characterized, particularly in the oncology arena. CBD's interaction with the TRP receptor family has been an exciting line of research and has been implicated in many of CBD's observed therapeutic effects (Costa et al., 2004; Zador and Wollemann, 2015; Whalley et al., 2018). The TRP family is a multigene, superfamily of ion channels that produce a range of physiological effects (Samanta et al., 2018). In particular, the TRPV1 receptor, a calcium ion channel found to be localized to the IMM of the mitochondria in nonneuronal cells (Kim et al., 2017), appears to have diverse cellular effects after exposure to $\mathrm{CBD}$, with variability dependent on cell type, physiologic state, and CBD dosage (Costa et al., 2004; Zador and Wollemann, 2015; Whalley et al., 2018). TRPV1 activation induces cell death after treatment with the TRPV1 agonist, capsaicin, via a rapid increase in intracellular calcium (Ramírez-Barrantes et al., 2018). CBD-induced intramitochondrial calcium overload has been implicated in the formation of the fatal mitochondrial permeability transition pore (mPTP) and subsequent CBD-mediated cell death, independent of the CB1/CB2 receptors (Rimmerman et al., 2013; Wu et al., 2018; Olivas-Aguirre et al., 2019). Here, we sought to investigate if TRPV1 channel-mediated increases in mitochondrial calcium flux after CBD treatment might explain our observations. Pharmacologic inhibition of the TRPV1 receptor with IRTX, however, did not produce any protective effects across cell lines, suggesting the TRPV1 receptor is not involved with CBD-mediated cell death in our model. The VDAC1-Mitochondrial Calcium Uniporter complex, an outer and inner mitochondrial membrane mediator of calcium uptake from the cytosol, is being investigated in CBD mediated cell death (Rimmerman et al., 2013). Research has demonstrated colocalization and direct interaction of CBD and VDAC1, heavily implicating this channel in observed cellular energy pathologies (Rimmerman et al., 2013). Pharmacologic inhibition of VDAC1 with DIDS produced stark protective effects on cell viability, suggesting that VDAC1 is a major contributor to CBD-mediated cell death. While pharmacologic inhibition of VDAC1 produced results in support of our hypothesis, we cannot exclude other off-target effects of DIDS, such as caspase inhibition (Benitez-Rangel et al., 2015). Ideally, future studies will investigate individual genetic knockout or knockdown of the TRPV1, MCU, and VDAC1 channels to clarify their role in CBD-mediated pathogenesis.

Targeted dysregulation of mitochondrial bioenergetics has become a leading hypothesis for the observed CBD anticancer effects (Rimmerman et al., 2013; Wu et al., 2018; Jeong et al., 2019; Olivas-Aguirre et al., 2019). In this present study we show a significant perturbation of mitochondrial OCR and ECAR soon after treatment with both lethal and non-lethal doses of CBD that appears to persist for almost $6 \mathrm{~h}$ post-treatment. Previous studies have demonstrated CBD's ability to alter mitochondrial membrane potential, (Rimmerman et al., 2013; Olivas-Aguirre et al., 2019), which is delicately tied to Complex I function. These findings are corroborated qualitatively by the dramatic ultrastructural changes in mitochondria seen as soon as $2 \mathrm{~h}$ post-treatment with a lethal dose of CBD $(10 \mu \mathrm{g} / \mathrm{ml})$. Across all cell lines, these observed ultrastructural changes at 2 -h postlethal treatment support the significant drop of OCR observed via 
the Seahorse XFe24 at approximately $150 \mathrm{~min}$ (120 min post treatment). We hypothesize, at lethal concentrations, CBD alters permeability of the VDAC1 channel to facilitate a rapid influx of calcium into the mitochondria which leads to a loss of mitochondrial function due to perturbation of membrane potential, release of reactive oxygen species (ROS), and depletion of ATP. This dysfunction also results in the formation of the mPTP, mitochondrial swelling, and subsequent cell death. Previous studies have demonstrated a cellular-protective effect of cyclosporine A, a mPTP inhibitor (Sharov et al., 2007) but not with FK-506, a calcineurin inhibitor (Dumont, 2000). The respective mechanism of action of these two drugs suggests the involvement of the MPTP in CBD-mediated cell death (Wu et al., 2018).

In previous CBD studies, utilization of the MTT, resazurin, or other related metabolic assays has been the standard for assessing cell viability and cytotoxicity analysis (Shrivastava et al., 2011; De Petrocellis et al., 2013; Solinas et al., 2013; Lukhele and Motadi, 2016). The stark disparity between our resazurin reduction fluorescence data and cell proliferation data suggest that mitochondrial Complex I function is compromised at doses of CBD that have little to no effect on cell viability. Therefore, cell viability assays dependent on mitochondrial respiration may overestimate CBD-mediated cytotoxicity and our results discourage continued use of these assays for CBD related studies. This also raises the tantalizing possibility that $\mathrm{CBD}$ might have therapeutic effects at sub-cytotoxic doses that could prove synergistic with other standard interventions such as temozolomide, external beam radiation, and perhaps ascorbic acid.

The grave prognosis and relatively ineffective currently available treatment strategies make further glioma therapeutic research crucial. The growing body of knowledge of the pharmacology, anticancer effects, and other therapeutically relevant properties of cannabidiol reveal the exciting potential of $\mathrm{CBD}$ as a potential clinical therapeutic.

\section{REFERENCES}

Bakas, T., Van Nieuwenhuijzen, P. S., Devenish, S. O., Mcgregor, I. S., Arnold, J. C., and Chebib, M. (2017). The Direct Actions of Cannabidiol and 2-arachidonoyl Glycerol at GABA A Receptors. Pharmacol. Res. 119, 358-370. doi:10.1016/ j.phrs.2017.02.022

Benitez-Rangel, E., Maria Cristina, L.-M., García, L., and Guerrero-Hernández, A. (2015). DIDS (4,4'-Diisothiocyanatostilbene-2,2'-Disulfonate) Directly Inhibits Caspase Activity in HeLa Cell Lysates. Cel Death Discov. 1, 15037. doi:10.1038/cddiscovery.2015.37

Calvaruso, G., Pellerito, O., Notaro, A., and Giuliano, M. (2012). Cannabinoidassociated Cell Death Mechanisms in Tumor Models. Int. J. Oncol. 41, 407-413. doi:10.3892/ijo.2012.1476

Costa, B., Giagnoni, G., Franke, C., Trovato, A. E., and Colleoni, M. (2004). Vanilloid TRPV1 Receptor Mediates the Antihyperalgesic Effect of the Nonpsychoactive Cannabinoid, Cannabidiol, in a Rat Model of Acute Inflammation. Br. J. Pharmacol. 143, 247-250. doi:10.1038/sj.bjp.0705920

De Gregorio, D., Mclaughlin, R. J., Posa, L., Ochoa-Sanchez, R., Enns, J., LopezCanul, M., et al. (2019). Cannabidiol Modulates Serotonergic Transmission and Reverses Both Allodynia and Anxiety-like Behavior in a Model of Neuropathic Pain. Pain 160, 136-150. doi:10.1097/j.pain.0000000000001386

De Petrocellis, L., Ligresti, A., Schiano Moriello, A., Iappelli, M., Verde, R., Stott, C. G., et al. (2013). Non-THC Cannabinoids Inhibit Prostate Carcinoma

\section{DATA AVAILABILITY STATEMENT}

The original contributions presented in the study are included in the article/Supplementary Material, further inquiries can be directed to the corresponding author.

\section{AUTHOR CONTRIBUTIONS}

CG, DR, DG, and SM contributed equally to research design, analytic tools/reagents and writing/revision of the article. CG and DR contributed equally to the conduction of experiments and data analysis.

\section{FUNDING}

This work was supported through a non-competitive grant funded by the Extract Labs ${ }^{\mathrm{TM}}$, headquartered in Boulder, Colorado. This work was also supported in part by the Shipley University Chair in Comparative Oncology held by DG.

\section{ACKNOWLEDGMENTS}

We would like to thank Dr. Pete Dickinson (University of California, Davis) for kindly providing us with the canine glioblastoma cell lines.

\section{SUPPLEMENTARY MATERIAL}

The Supplementary Material for this article can be found online at: https://www.frontiersin.org/articles/10.3389/fphar.2021.725136/ full\#supplementary-material

Growthin Vitroandin Vivo: Pro-apoptotic Effects and Underlying Mechanisms. Br. J. Pharmacol. 168, 79-102. doi:10.1111/j.14765381.2012.02027.x

Dondelinger, Y., Hulpiau, P., Saeys, Y., Bertrand, M. J. M., and Vandenabeele, P. (2016). An Evolutionary Perspective on the Necroptotic Pathway. Trends Cel Biol. 26, 721-732. doi:10.1016/j.tcb.2016.06.004

Dumont, F. J. (2000). FK506, an Immunosuppressant Targeting Calcineurin Function. Cmc 7, 731-748. doi:10.2174/0929867003374723

Dzierżanowski, T. (2019). Prospects for the Use of Cannabinoids in Oncology and Palliative Care Practice: A Review of the Evidence. Cancers (Basel) 11, (2):129. doi:10.3390/cancers11020129

Hadziahmetovic, M., Shirai, K., and Chakravarti, A. (2011). Recent Advancements in Multimodality Treatment of Gliomas. Future Oncol. 7, 1169-1183. doi:10.2217/fon.11.102

Hermanson, D. J., and Marnett, L. J. (2011). Cannabinoids, Endocannabinoids, and Cancer. Cancer Metastasis Rev. 30, 599-612. doi:10.1007/s10555-011-9318-8

Herranz, C., Fernández, F., Martín-Ibáñez, R., Blasco, E., Crespo, E., De La Fuente, C., et al. (2016). Spontaneously Arising Canine Glioma as a Potential Model for Human Glioma. J. Comp. Pathol. 154, 169-179. doi:10.1016/j.jcpa.2015.12.001

Huang, C., Luo, Y., Zhao, J., Yang, F., Zhao, H., Fan, W., et al. (2013). Shikonin Kills Glioma Cells through Necroptosis Mediated by RIP-1. PLoS One 8, e66326. doi:10.1371/journal.pone.0066326

Jacobsson, S. O. P., Rongård, E., Stridh, M., Tiger, G., and Fowler, C. J. (2000). Serum-dependent Effects of Tamoxifen and Cannabinoids upon C6 Glioma 
Cell Viability. Biochem. Pharmacol. 60, 1807-1813. doi:10.1016/s00062952(00)00492-5

Jeong, S., Jo, M. J., Yun, H. K., Kim, D. Y., Kim, B. R., Kim, J. L., et al. (2019). Cannabidiol Promotes Apoptosis via Regulation of XIAP/Smac in Gastric Cancer. Cel Death Dis. 10, 846. doi:10.1038/s41419-019-2001-7

Kendall, D. A., and Yudowski, G. A. (2016). Cannabinoid Receptors in the Central Nervous System: Their Signaling and Roles in Disease. Front Cel Neurosci. 10, 294. doi:10.3389/fncel.2016.00294

Kim, H. K., Noh, Y. H., Nilius, B., Ko, K. S., Rhee, B. D., Kim, N., et al. (2017). Current and Upcoming Mitochondrial Targets for Cancer Therapy. Semin. Cancer Biol. 47, 154-167. doi:10.1016/j.semcancer.2017.06.006

Koehler, J. W., Miller, A. D., Miller, C. R., Porter, B., Aldape, K., Beck, J., et al. (2018). A Revised Diagnostic Classification of Canine Glioma: Towards Validation of the Canine Glioma Patient as a Naturally Occurring Preclinical Model for Human Glioma. J. Neuropathol. Exp. Neurol. 77, 1039-1054. doi:10.1093/jnen/nly085

Lincoln, F. A., Imig, D., Boccellato, C., Juric, V., Noonan, J., Kontermann, R. E., et al. (2018). Sensitization of Glioblastoma Cells to TRAIL-Induced Apoptosis by IAP- and Bcl-2 Antagonism. Cel Death Dis. 9, 1112. doi:10.1038/s41419018-1160-2

Lukhele, S. T., and Motadi, L. R. (2016). Cannabidiol rather Than Cannabis Sativa Extracts Inhibit Cell Growth and Induce Apoptosis in Cervical Cancer Cells. BMC Complement. Altern. Med. 16, 335. doi:10.1186/s12906-016-1280-0

Magrì, A., Reina, S., and De Pinto, V. (2018). VDAC1 as Pharmacological Target in Cancer and Neurodegeneration: Focus on its Role in Apoptosis. Front. Chem. 6: 108. doi:10.3389/fchem.2018.00108

Mandal, P., Berger, S. B., Pillay, S., Moriwaki, K., Huang, C., Guo, H., et al. (2014). RIP3 Induces Apoptosis Independent of Pronecrotic Kinase Activity. Mol. Cel 56, 481-495. doi:10.1016/j.molcel.2014.10.021

Massi, P., Solinas, M., Cinquina, V., and Parolaro, D. (2013). Cannabidiol as Potential Anticancer Drug. Br. J. Clin. Pharmacol. 75, 303-312. doi:10.1111/ j.1365-2125.2012.04298.x

Mckenzie, B. A., Mamik, M. K., Saito, L. B., Boghozian, R., Monaco, M. C., Major, E. O., et al. (2018). Caspase-1 Inhibition Prevents Glial Inflammasome Activation and Pyroptosis in Models of Multiple Sclerosis. Proc. Natl. Acad. Sci. USA 115, E6065-E6074. doi:10.1073/pnas.1722041115

Newton, K., Dugger, D. L., Wickliffe, K. E., Kapoor, N., De Almagro, M. C., Vucic, D., et al. (2014). Activity of Protein Kinase RIPK3 Determines whether Cells Die by Necroptosis or Apoptosis. Science 343, 1357-1360. doi:10.1126/ science. 1249361

O'sullivan, S. E. (2016). An Update on PPAR Activation by Cannabinoids. Br. J. Pharmacol. 173, 1899-1910. doi:10.1111/bph.13497

Olivas-Aguirre, M., Torres-López, L., Valle-Reyes, J. S., Hernández-Cruz, A., Pottosin, I., and Dobrovinskaya, O. (2019). Cannabidiol Directly Targets Mitochondria and Disturbs Calcium Homeostasis in Acute Lymphoblastic Leukemia. Cel Death Dis. 10, 779. doi:10.1038/s41419-019-2024-0

Orozco, S., and Oberst, A. (2017). RIPK3 in Cell Death and Inflammation: the Good, the Bad, and the Ugly. Immunol. Rev. 277, 102-112. doi:10.1111/ imr. 12536

Ramírez-Barrantes, R., Córdova, C., Gatica, S., Rodriguez, B., Lozano, C., Marchant, I., et al. (2018). Transient Receptor Potential Vanilloid 1 Expression Mediates Capsaicin-Induced Cell Death. Front. Physiol. 9, 682. doi:10.3389/fphys.2018.00682

Rimmerman, N., Ben-Hail, D., Porat, Z., Juknat, A., Kozela, E., Daniels, M. P., et al. (2013). Direct Modulation of the Outer Mitochondrial Membrane Channel, Voltage-dependent Anion Channel 1 (VDAC1) by Cannabidiol: a Novel Mechanism for Cannabinoid-Induced Cell Death. Cell Death Dis. 4, e949. doi:10.1038/cddis.2013.471

Rossmeisl, J. H., Jones, J. C., Zimmerman, K. L., and Robertson, J. L. (2012). Survival Time Following Hospital Discharge in Dogs with Palliatively Treated Primary Brain Tumors. J. Am. Vet. Med. Assoc. 242, 193-198. doi:10.2460/ javma.242.2.193

Samanta, A., Hughes, T. E. T., and Moiseenkova-Bell, V. Y. (2018). Transient Receptor Potential (TRP) Channels. Subcell Biochem. 87, 141-165. doi:10.1007/ 978-981-10-7757-9_6

Sharov, V. G., Todor, A., Khanal, S., Imai, M., and Sabbah, H. N. (2007). Cyclosporine A Attenuates Mitochondrial Permeability Transition and
Improves Mitochondrial Respiratory Function in Cardiomyocytes Isolated from Dogs with Heart Failure. J. Mol. Cell Cardiol. 42, 150-158. doi:10.1016/j.yjmcc.2006.09.013

Shrivastava, A., Kuzontkoski, P. M., Groopman, J. E., and Prasad, A. (2011). Cannabidiol Induces Programmed Cell Death in Breast Cancer Cells by Coordinating the Cross-Talk between Apoptosis and Autophagy. Mol. Cancer Ther. 10, 1161-1172. doi:10.1158/1535-7163.mct-10-1100

Silver, R. J. (2019). The Endocannabinoid System of Animals. Animals (Basel) 9: 686. doi:10.3390/ani9090686

Solinas, M., Massi, P., Cinquina, V., Valenti, M., Bolognini, D., Gariboldi, M., et al. (2013). Cannabidiol, a Non-psychoactive Cannabinoid Compound, Inhibits Proliferation and Invasion in U87-MG and T98G Glioma Cells through a Multitarget Effect. PLoS One 8, e76918. doi:10.1371/journal.pone.0076918

Stampanoni Bassi, M., Gentile, A., Iezzi, E., Zagaglia, S., Musella, A., Simonelli, I., et al. (2019). Transient Receptor Potential Vanilloid 1 Modulates Central Inflammation in Multiple Sclerosis. Front. Neurol. 10, 30. doi:10.3389/ fneur.2019.00030

Stupp, R., Hegi, M. E., Mason, W. P., Van Den Bent, M. J., Taphoorn, M. J., Janzer, R. C., et al. (2009). Effects of Radiotherapy with Concomitant and Adjuvant Temozolomide versus Radiotherapy Alone on Survival in Glioblastoma in a Randomised Phase III Study: 5-year Analysis of the EORTC-NCIC Trial. Lancet Oncol. 10, 459-466. doi:10.1016/s1470-2045(09)70025-7

Thomas, R., Duke, S. E., Wang, H. J., Breen, T. E., Higgins, R. J., Linder, K. E., et al. (2009). 'Putting Our Heads Together': Insights into Genomic Conservation between Human and Canine Intracranial Tumors. J. Neurooncol. 94, 333-349. doi:10.1007/s11060-009-9877-5

Uhm, J. H., and Porter, A. B. (2017). Treatment of Glioma in the 21st Century: An Exciting Decade of Postsurgical Treatment Advances in the Molecular Era. Mayo Clinic Proc. 92, 995-1004. doi:10.1016/j.mayocp.2017.01.010

Whalley, B. J., Gray, R. A., Stott, C. G., and Jones, N. A. (2018). Antiseizure Properties of Cannabidiol (CBD) Are Attenuated in the Absence of Transient Receptor Potential Vanilloid 1 (TRPV1) Receptors (S53.004). Neurology 90, S53-S004.

Wu, H.-Y., Huang, C.-H., Lin, Y.-H., Wang, C.-C., and Jan, T.-R. (2018). Cannabidiol Induced Apoptosis in Human Monocytes through Mitochondrial Permeability Transition Pore-Mediated ROS Production. Free Radic. Biol. Med. 124, 311-318. doi:10.1016/j.freeradbiomed.2018.06.023

York, D., Sproul, C. D., Chikere, N., Dickinson, P. J., and Angelastro, J. M. (2018). Expression and Targeting of Transcription Factor ATF5 in Dog Gliomas. Vet. Comp. Oncol. 16, 102-107. doi:10.1111/vco.12317

Zádor, F., and Wollemann, M. (2015). Receptome: Interactions between Three PainRelated Receptors or the "Triumvirate" of Cannabinoid, Opioid and TRPV1 Receptors. Pharmacol. Res. 102, 254-263. doi:10.1016/j.phrs.2015.10.015

Zhou, H., Zhu, P., Guo, J., Hu, N., Wang, S., Li, D., et al. (2017). Ripk3 Induces Mitochondrial Apoptosis via Inhibition of FUNDC1 Mitophagy in Cardiac IR Injury. Redox Biol. 13, 498-507. doi:10.1016/j.redox.2017.07.007

Zou, S., and Kumar, U. (2018). Cannabinoid Receptors and the Endocannabinoid System: Signaling and Function in the Central Nervous System. Int. J. Mol. Sci. 19: 833. doi:10.3390/ijms 19030833

Conflict of Interest: The authors declare that the research was conducted in the absence of any commercial or financial relationships that could be construed as a potential conflict of interest.

Publisher's Note: All claims expressed in this article are solely those of the authors and do not necessarily represent those of their affiliated organizations, or those of the publisher, the editors and the reviewers. Any product that may be evaluated in this article, or claim that may be made by its manufacturer, is not guaranteed or endorsed by the publisher.

Copyright $\odot 2021$ Gross, Ramirez, McGrath and Gustafson. This is an open-access article distributed under the terms of the Creative Commons Attribution License (CC BY). The use, distribution or reproduction in other forums is permitted, provided the original author(s) and the copyright owner(s) are credited and that the original publication in this journal is cited, in accordance with accepted academic practice. No use, distribution or reproduction is permitted which does not comply with these terms. 